\title{
Bireyin Sıkıntıya Dayanması Üzerine Sosyal Medyanın Rolü
}

\author{
DOI: 10.26466/opus.537720 \\ * \\ Murat Sezgin* - İdris Simșek $^{* *}$ \\ * Doç. Dr, Uşak Üniversitesi, İletişim Fakültesi, Uşak/Türkiye \\ E-Posta: murat.sezgin@usak.edu.tr \\ ORCID: 0000-0003-2200-3301 \\ ** Y. L. Öğrencisi, Uşak Üniversitesi, Sosyal Bilimler Enstitüsü, Uş̧ak/Türkiye \\ E-Posta: idrissimsek34@gmail.com \\ ORCID: $\quad \underline{0000-0003-2939-7585}$
}

Öz

Üniversite öğrencilerinin çoğunun doğup büyüdüğ̈̈ çevrenin dışında bir şehirde eğitim hayatına devam etme durumları onları mevcut sosyal çevrelerinden de uzaklaştırmaktadır. Bu doğrultuda bireyler hayatlarına yeni edindikleri sosyal çevre ile devam ederken yalnızlık ve sıkıntılarından kurtulma gibi amaçlarla sosyal medya ortamlarından istifade etmektedir. Bu araştırma ekseninde de, "Bireyin Sıkıntıya Dayanma Durumu" ile "Sosyal Medya Kullanımı" arasındaki olgu ilişkisel bağlamda ele alınmıştır. İlgili çerçevede, Sanal Sosyalleşme Ölçeği (SSÖ) ve Sıkıntıya Dayanma Ölçeği (SDÖ) kullanılarak toplamda 400 üniversite öğrencisi üzerinde bir alan çalışması yapılmıştır. Anket formları ile elde edilen veriler SPSS 24.0 (Statistical Package for the Social Science) programe ile analiz edilmiştir. Araştırma sonunda öğrencilerin sıkıntıya dayanma durumları, olumsuz duygulanımları ve paylaşımda bulunmaları arasında anlamlı ilişki olduğu tespit edilirken sosyalleşme boyutu ile sıkıntıya dayanma ve sıkıntıdan kurtulma alt boyutları arasında da anlamlı ilişkiler olduğu görülmüştür.

Anahtar Kelimeler: Sıkıntıya dayanma, Sıkıntı, Kaygı, Üzüntü, Sosyal Medya 


\title{
The Role of The Social Media on The Resistance of The Individual to Distress
}

\begin{abstract}
Most of the university students continue their education in a city outside of the environment they were born and raised. This distances them from their existing social environment. In this respect, individuals continue their lives with their newly acquired social environment and benefit from social media environments with the purpose of getting rid of their loneliness and distress. In this research axis, the relationship between "The Status of Coping with Distress" and "Social Media Usage" is discussed in the context of the relationship. In this context, a field study was conducted on a total of 400 university students using the "Virtual Socialization Scale" and the "Resistance to Abuse Scale". The data obtained from the questionnaire forms were analyzed with SPSS 24.0 program. At the end of the study, it was determined that there was a significant relationship between students' being subject to distress, negative affect and sharing. There were also significant relationships between socialization dimension and distress-based and distress-related sub-dimensions.
\end{abstract}

Keywords: Distress tolerance, Trouble, Sadness, Anxiety, Social Media 


\section{Giriş}

Yaratılış gereği sosyal bir varlık olan insanın, toplumun diğer üyeleriyle kurduğu iletişim ve sosyalleşme durumu, bireyi topluma ve hayata adapte eden yegâne unsurlardan birisidir. Bu işlevi yerine getiremeyen bireyler toplumdan dışlanmışlık hissi yaşayacağı gibi aynı zamanda içsel olarak da yalnızlık hissine kapılmaktadırlar.

Gelişen teknolojiyle ortaya çıan iletişim araçlarının bireyler arası iletişime zaman ve mekân sınırlaması olmaksızın elveriş sağladığı bilinen bir gerçektir. Öte yandan söz konusu araçların sosyalleşmeye ve asosyalleşmeye sevk ettiğine dair çeşitli çalışmalar da mevcuttur (Kaya, 2013, s.156). Gelişen bu teknolojilerle beraber özelikle web 2.0' ile ortaya çıkan; Facebook, Twitter, Instagram gibi sosyal ağlar, bireylerin karakter, fiziksel ve sosyo-psikolojik yapılarını etkilediği gibi boş zamanlarını da şekillendirmektedir (Blanco, 2014, s.190). Teknolojik belirleyicilik kuramının öncüleri olan Macluhan ve Innis de insan davranışlarının merkezinde teknolojinin yer aldığını, bireylerin davranışlarını kontrol eden unsurlardan birisinin de medya olduğunu ve iletişim ağlarının insan algısı üzerinde köklü değişiklere sebebiyet verdiğini ifade etmektedir (Carey, 1967, s.5-6).

Sosyal ağlar bireyler açısından kısa süreli küçük formatlara dayanan rahatlama, sıkıntı giderme, haz, keyifalma, eğlence sağlama gibi işlevlerin yanında, katılım, yaratıcılık, iş birliği, kolektif bilgi, proje üretimi ve hobi gibi olgular için de ideal bir ortam vadetmektedir. Kısacası bu sanal ortamlar bireyleri sıkıntılarından uzaklaştıran iletişim, sosyalleşme, eğlence ve keyif alma aracı haline gelmişlerdir (Blanco, 2014, s.191-192). Bu durum olumlu olarak addedilmesine karşın eleştirel bilimci Mcluhan gibi düşünürler tarafından çeşitli olumsuz yönleriyle de eleştirilmektedir. Söz konusu olumsuz durumlar; gelişen iletişim teknolojilerinin yalnızca iletişim kurmayı artırmayacağı bunun yanında insanları işlevsizleştireceği dolayısıyla da giderek insanlığın ürettiği teknolojinin tutsağı konumuna geleceği şeklinde aktarılmaktadır (Erdoğan ve Alemdar, 2005, s.159). Diğer bir çalışmanın çıtıları ise; 2000 yılında 1829 yaş aralığındaki gençlerin \%70'inin internet kullandığını, 2009'da ise bu oranın \%93'e çıktı̆̆ını belirtmektedir. Nitekim bu gün bu yaş grubunda bulunan hemen hemen herkes internet kullanmaktadır (Steinberg, 2014, 
s.158). Schools.com tarafından yayınlanan infografiğe göre de özellikle genç insanların yaşadığ çabası içerisinde olduğu böylece birçok özel anı kaçırdığı aktarılmaktadır. Anın tadını çıkarmak yerine sosyal medyada paylaşım çabası gösteren 1824 yaş arasındaki gençlerin \%43'lük diliminin, planlarını sosyal mecra üzerinden gerçekleştirdiği ifade edilmekte, gençlerin bir çoğunun kendini abartılı biçimlerde tanımlayarak birbirlerine karşı yalan söylediği ve yüz yüze iletişim kurmaktansa online iletişim biçimlerini tercih ettiği gözlenmektedir (Sanlav, 2014, s.89).

California State University'nin gerçekleştirdiği araştırmanın sonuçlarına göre de sosyal medyanın sebep olduğu olumsuz durumlar arasında; narsist kişilik bozukluğu dikkat bozukluğu, sıkıntıya girme durumu, bağımlılık, şizofreni, kaygı, depresyon gibi vakalar siralanmaktadır. İnternet bağımlılığının giderek arttığını belirten uzmanlar, yoğun internet kullanımının, depresyon, stres, kaygı ve sıkıntılı olma olasılıklarını 2.5 kat artırdığını ifade etmektedir (Sanlav, 2014, s.91-102). Aynı zamanda gençlik enstitüleri, üniversiteler ve hükümetler gibi kuruluşlar da gerçekleştirdikleri araştırmalarda gençlerin sosyal ağ kullanımı altında yatan temel nedenleri irdelemektedir. Söz konusu kurumların yaptıkları araştırmaların bulgularının da gösterdiği üzere, sosyal medya daha çok sosyalleşme, iletişim kurma, etkileşim içinde olma ve özellikle sıkıntılı ruh halinden uzaklaşma amaçlı kullanılmaktadır (Blanco, 2014, s.199).

İlgili araştırmalardan yola çıkılarak bu araştırma kapsamında sosyal medyanın sıkıntıya dayanma durumuyla olan ilişkisi ele alınmaktadır. Konunun daha iyi aktarılabilmesi adına sıkıntı, kaygı ve üzüntü gibi konular ele alındıktan sonra üniversite öğrencileri üzerinde gerçekleştirilen uygulama aşamasına geçilecektir.

\section{Sıkıntıya Dayanma, Sıkıntı, Kaygı ve Üzüntü Kavramları}

Bireyler yaşamları süresince, üstesinden gelemediği, çözüm üretmede zorlandığ1 birden çok problemle karşılaşmaktadır. Bireyin psikolojik yönden zorlandığı, üzüntü, umutsuzluk ve mutsuzluk duyduğu negatif duygular hissettiği vaziyetlerdeki hissiyatı, sıkıntı olarak tanımlanmaktadır. Sıkıntıya dayanma ise bireylerin bu negatif duyguları hafifletmek 
için eylemleriyle gerçekleştirdiği, uzaklaşma durumu olarak görülebilir (Leyro ve ark, 2010, s.577). Simon ve Gaher (2005, s.83), ise sıkıntıya dayanma durumunu olumsuz psikolojik vaziyetleri tecrübe etmek ve bu vaziyetlere dayanma kapasiteleri olarak tanımlamaktadır. Öte yandan Buckner ve arkadaşları sıkıntıya dayanmayı fiziksel veya bilişsel eylemlerden çok duygusallığa bağlı bir eylem olarak ele almaktadır. Çoğu zaman bu duygusal vaziyeti hafifletmek amaciyla bireylerin eyleme döktügü bir gayret vardır. Sıkıntıya dayanamayan bireyler negatif vaziyetler karşısında imtina etme ya da rahatlama eylemlerine başvurabilmektedirler (Buckner ve ark., 2007, s.1958). Sosyal mecraların bireyler tarafından kullanılması da sıkıntının giderilmesinde kullanılan rahatlama ve kaçınma eylemleri arasında yer almaktadır (Erbaş, 2019, s.11).

Simond ve Gaher'ın (2005, s.91-97) gerçekleştirdiği araştırmaya göre sıkıntıya dayanmada zayıf kişiliğe sahip bireyler, sıkıntıyı çekilmez olarak görmekte, sıkıntıyı kabullenememekte, sıkıntılı ruh halinden utanç duymakta ve sıkıntı konusunda kendisini diğer insanlara nazaran daha güçsüz hissetmektedir.

Sıkıntıya dayanma; depresyon, ilgi kaybı, umutsuzluk, kaygı, gerginlik, huzursuzluk ve duygusal acı çekme kavramlarıyla ilişkilendirilebilir (Vaag vd., 2016, s.242-244). Üniversite öğrencilerinin de belirsizlik ya da sıkıntılı ruh hali gibi sebeplerden kaynaklı kaygı yaşadığı bilinmektedir (Güler, 2018, s.1047-1048). Öte yandan kayg1, depresyon, işlevsel yetersizlik, kişilik özellikleri ve davranışsal problemleri betimlemede de sıkıntıya dayanma kavramından faydalanılmaktadır (Shih ve ark.,2006, s.1164). Sıkıntıya dayanma sözcügünü daha iyi anlamak için ilgili terimle alakalı olan sıkıntı, kaygı ve üzüntü sözcüklerini de açıklamakta fayda vardir.

- Sıkıntı: bezginlik, sorun, mesele sendrom, bir şeyden mahrum bırakılma ve tekdüzelik gibi sebeplerden doğan; giderilmediği durumda sürekli fiziksel ve ruhsal yorgunluğa sebep olan, cefa eziyet, ızdırap durumudur (TDKa, 2019). Sıkıntı kavramı bireylerin kendi öz mevcudiyetiyle de ilişkilendirilmektedir. Bireylerde "kendilik" bilinci vardır ve bu öz bilincin temelinde derin bir anlayışa ulaşmadığı zaman, bireyde sıkıntı, umutsuzluk başlar. Hegel ise bireylerin belirli bir bilinç seviyesine ulaştıktan sonra kimlik edinme ihtiyacı duyduğunu, bu kimlik arayışının, doğal olarak 
"sıkıntı" kavramıyla da bireyi tanıştıracağını söylemektedir (Sevendsen, 2008, s.8-10).

- Kaygi: Freud'a göre kaygı korkudan ayrılmaktadır. Korkuyu dıştan gelen tehditlerden kaynaklı eylemler olarak tanımlarken kaygıyı ise içten gelen tehlikelere yönelik verilen tepki şeklinde tanımlamaktadır. Aynı şekilde Freud kaygı sözcügünü̈, tehlikeli bir eylemle karşılaşıldığında etkili bir tepkide bulunamama ve olay karşısında dirençsiz kalma neticesinde psikolojik şekilde bilinçsizce oluşan bir duygu şeklinde görmektedir (Morgan, 2011, s.291). Cüceloğlu da kaygı sözcügüüü tam anlamıyla bir tanımlamaya sığdırmanın zor olduğuna değinerek kaygıyı korku, üzüntü, sonuçları kestirememe, başarısızlık düşüncesi gibi birden çok duyguyla ilişkilendirerek ele almaktadır (Cüceloğlu, 2006, s.276). Geniş anlamıyla Elis (1994) ise kaygıyı, hissedilen bir tehlikeye hazırlanma esnasında algılanan zayıflık duygusunun yaşandığı duygusal ruh hali olarak tanımlamaktadır.

- Üzüntü: Üzüntü, her hangi bir kötü durumla karşılaşıldığında bireyde görülen ilk duygudur. Psikolojik travma karşısında beliren duygu bu duruma bağlı olarak bireyin kendini halsiz, depresif hissetmesidir. Üzüntü bireylerde hayattan tat alma duygusunda azalma şeklinde belirginleşir (Tarhan, 2012, s.195). Konrad ve Henedl (2001, s.153) üzüntü kavramının, insanlarda en çok göz bölgesinde belirginlik gösterdiğini ve depresyon, mutsuzluk, acı çekme veya bir şeyi kaybetme durumlarında gösterilen tepki olarak tanımlamışlardır. TDK'da ise kısaca üzüntü kavramı, olması istenilmeyen davranışlardan doğan ruhsal tedirginlik olarak tanımlanır (TDKb, 2019).

\section{Sosyal Medya ve Gelişim Serüveni}

Terim olarak yaklaşık 15 yıl önce hayatımıza giren ve son dönemlerde hayatımızda yoğun şekilde yer edinen sosyal medyanın geçmişi 70'li yıllara dayanmaktadır. 1978 yılında iki bilgisayar meraklısı arkadaş olan Ward Cristensen ve Randy Suess arkadaşlariyla enformasyon paylaşımında bulunmak ve iletişim içerisinde olmak için BBS adlı yazılımı icat etmeleri ilk sosyal ağ örneği olarak görülmektedir. Bu süreçten 11 yll 
sonra İsviçre'de dünyanın ilk web sitesi kuruldu ve süreç hızlı bir şekilde gelişim göstermiştir. Öyle ki diğer insanlarla iletişim kurma amac1 güdülerek 1995 yılında MIRC programı geliştirilmiştir. (Sanlav, 2014, s.20). Sonrasinda Blogger 1999, MySpace 2003, Skype 2003, LinkedIn 2003, Flicker 2004, Facebook 2004, Youtube 2005, Instagram 2010 gibi sosyal medya ağları ortaya çıkmıştır (Franch ve Carrillo, 2014, s.234). Bahsi geçen öncü uygulamalarla birlikte sosyal medya, daha birçok yeni uygulamayı da bünyesine dahil ederek günümüz toplumda (Kara, 2013, s.65) ve kurumlarda özellikle kriz dönemlerinde önemli rol oynamaktadır (Duğan, 2018, s.309).

Gündelik hayat davranışlarının oluşumundan, bireylerin birbirleriyle olan iletişimlerine, kamusal alandaki hareketlerden, bireyin kimlik inşa süreçlerine ve toplumsal oluşumların ortaya çıkış süreçlerine varıncaya kadar çok sayıda etkiye sahip olan sosyal mecralar, yeni medyanın kendi özellikleri kapsamında şekillendirdiği özgün, popüler ve güçlü platformlar olarak değerlendirilmektedir (Göker, 2015, s.400). Donath ve Body, insanların tanımadıkları kişilerin sosyal çevresini ve profilini inceleyerek o kişi ile ilgili izlenim oluşturduklarını ve bu izlenimde, kişinin paylaşımları kadar arkadaş listesinin sayısal miktarının da etkili olduğunu savunmaktadırlar (Donath ve Boyd' dan akt. Kara, 2013, s.53).

Donath ve Boyd' un da ifade ettiği gibi insanların en temel ihtiyacı olan sosyal çevre edinme, teşhis etme ve diğer insanlara karşı olan meraka hitap eden sosyal paylaşım ağları, bugün milyarlarca insan tarafından ziyaret edilen bir fenomen haline gelmiştir (Kara, 2013,s.53). Sosyal ağlarla beraber ilişkilerin altyapısında da değişmeler meydana gelerek, her bir enformasyon sadece bir araştırma ötemizde bulunmaktadır. Tanışmak istediğimiz insanların bir bağlantı ötemizde olduğu fikri giderek yaygınlık kazanmaktadır (Jarvis,2012, s.63). Dolayısıyla sosyal mecralar, bir takım ortak karakteristik özellikleri bünyesinde barındıran şemsiye görevi görmektedir. Bu sebepten ötürü, gerek Facebook, Instagram, Twitter, gerekse Flicker, Whatsapp veya Youtube, Tumblr gibi uygulamalar özünde farklı araçlar olsa da geniş bir çerçevede sosyal medya evreninin bileşenlerini oluşturmaktadırlar (Kara, 2013, s.65).

Sosyal ağlar, "sosyal ve medya" sözcüklerinden oluşan (Murphy vd., 2013:4), özellikle gündelik yaşantıdan bir çok alışkanlığın değişimine sebebiyet veren ve daha çok genç kuşağın kullandığı (Güngör, 2011, 
s.111), bilgi, fikir ve düşünce paylaşımına olanak tanıyan iletişim kanallarıdır (Sayımer, 2008, s.123). İçerik denetimini kullanıcılara bırakan, her hangi bir mekân sınırlaması içermeyen ve web 2.0 tabanlı içerik hizmetlerinin oluşturulmasına olanak sağlayan, yeni iletişim kanalları sosyal mecra başlığı altında isimlendirilebilir (Kırık, 2013, s.75). En kapsamlı tanımlamayla sosyal medya; bireylerin diğer bireylerle görsel, video, bilgi ve metin paylaşmasına olanak veren platformlar olarak tanımlanabilir (Evans, 2008, s.33). Bilgi paylaşımında bulunmak ve iş birliğini kolaylaştırmak için tasarlanan sosyal medyanın (Steinberg, 2014, s.155), sosyal sözcüğü bireyler arsındaki çift taraflı etkileşimi önermektedir. Bu etkileşim doğrudan gerçekleşebileceği gibi, bir birey ile grup arasında veya sadece gruplar arasında da gerçekleşebilmektedir. Medya sözcügünde ise, ses, metin, mesaj vb. içerikler ile bilginin paylaşılmasını ve depolanmasını sağlayan kanallardır (Murphy vd., 2013, s.4).

İlgili alanyazından hareketle bireylerin çeşitli amaçlarla kullanım gösterdiği sosyal platformların sıkıntıya dayanma durumu ile olan ilişkisinin de araştırmaya değer bir konu olduğu düşülmektedir. Uygulama kısmında bu doğrultuda bir araştırma gerçekleştirilerek alan yazına katkı sağlanacağı varsayılmaktadır.

\section{Araştırmanın Amacı, Önemi ve Sınırlılıkları}

Üniversite öğrencilerinin çoğunluğunun doğup büyüdüğü çevrenin dışında bir şehirde eğitim hayatına devam etme durumları onları mevcut sosyal çevrelerinden de uzaklaştırmaktadır. Bu doğrultuda bireyler hayatlarına yeni edindikleri sosyal çevre ile devam etmekte ve yalnızlık ve sıkıntılarından kurtulma gibi amaçlarla sosyal medya ortamlarından istifade etmektedirler. $\mathrm{Bu}$ doğrultuda öğrencilerin sosyal medya kullanımları ile sıkıntıya dayanma durumları arasındaki ilişkinin incelenmeye değer bir konu olarak ortaya çıtığı düşünülmektedir. Dolayısıyla bu araştırmanın amacı üniversite öğrencilerinin yalnızlıktan kaynaklı sosyal medya kullanımı ile sıkıntıya dayanmaya durumları arasındaki ilişkinin çeşitli alt boyutlar kapsamında incelenmesidir. Araştırmanın genel hipotezleri şu şekildedir: 
H1 Öğrencilerin paylaşımda bulunma boyutu ile sıkıntıya dayanma boyutu arasında anlamlı ilişki vardır.

H2 Öğrencilerin paylaşımda bulunma boyutu ile sıkıntıdan kurtulma boyutu arasında anlamlı ilişki vardır.

H3 Öğrencilerin paylaşımda bulunma boyutu ile olumsuz duygulanım boyutu arasında anlamlı ilişki vardır.

H4 Öğrencilerin sosyalleşme boyutu ile sıkıntıya dayanma boyutu arasında ilişki anlamlı vardır.

H5 Öğrencilerin sosyalleşme boyutu ile sıkıntıdan kurtulma boyutu arasında ilişki anlamlı vardır.

H6 Öğrencilerin sosyalleşme boyutu ile olumsuz duygulanım boyutu arasında anlamlı ilişki vardır.

H7 Öğrencilerin yalnız hissetme boyutu ile sıkıntıya dayanma boyutu arasında anlamlı ilişki vardır.

H8 Öğrencilerin yalnız hissetme boyutu ile sıkıntıdan kurtulma boyutu arasında anlamlı ilişki vardır.

H9 Öğrencilerin yalnız hissetme boyutu ile olumsuz duygulanım boyutu arasında anlamlı ilişki vardır.

H10 Öğrencilerin güven boyutu ile sıkıntıya dayanma boyutu arasında anlamlı ilişki vardır.

H11 Öğrencilerin güven boyutu ile sıkıntıdan kurtulma boyutu arasında anlamlı ilişki vardır.

H12 Öğrencilerin güven boyutu ile olumsuz duygulanım boyutu arasında anlamlı ilişki vardır.

$\mathrm{Bu}$ bağlamda her ne kadar alanyazında sosyal medyanın gündelik alışkanlıkları değiştirerek yaşantımızın önemli bir paydaşı olduğu vurgulanmış olsa da (Köseoğlu, 2012, s.76-77; Alican ve Saban, 2013, s.13) bireylerin sıkıntıdan kurtulma noktasında sosyal medyanın rolünü amprik olarak ele alan araştırmalar oldukça sınırlıdır (Yalçın, 2015, s.63; Özdemir, Akçakanat, İzgüden, 2017, s.133-134). Dolayısıyla bu çalışma üniversite öğrencilerinin sıkıntıdan kurtulmaları noktasında sosyal medyanın rolünü ele alması yönüyle literatür için önem taşımaktadır. Öte yandan ilgili alan yazındaki çalışmaların oldukça sınırlı (Özdemir, Akçakanat, İzgüden, 2017, s.133-134; Yalçın, 2015, s.63; Erbaş, 2019, s.11-12) oluşu ve örneklem kümelerinin belirli temalarda yoğunlaşması nedeniyle 
de çalışma çıktılarının alan yazına katkı sağlayacağı düşünülmektedir. Nitekim bu çalışmada seçilen örneklem, spesifik bir fakülte yahut bölüm üzerinden seçilmemiş, üniversite öğrencilerini geniş bir yelpazede temsil edebilecek bir çalışma evreni üzerinden tercih edilmiştir. Dolayısıyla araştırma sonuçları üniversite öğrencisi olarak nitelendirilen çalışma evrenlerine daha rahat bir şekilde genellenebilmektedir.

Öte yandan araştırmanın sınırlamalarını; bütçe, zaman ve ulaşım gibi faktörler oluşturmaktadır. İlgili kısıtlar göz önünde bulundurularak çalışma evreni ulaşım kolaylığı göz önünde bulundurularak tercih edilmiştir.

\section{Metodoloji}

\section{Evren ve Örneklem}

Karasar'a (1984, s.115) göre bilimsel araştırmalarda iki tür evren vardır. Bunlardan ilki çalışılan konuya dair nesnelerin tümünü kapsayan ideal evren, diğeri ise çalışmanın zaman, bütçe, ulaşım gibi sınırlılıkları dahilinde ulaşılması mümkün olan çalışma evrenidir. Bu bağlamda gerçekleştirilen araştırmanın çalışma evrenini Uşak Üniversitesinin çeşitli bölümlerinde eğitimini sürdüren dördüncü sınıf öğrencileri oluşturmaktadır. Araştırmanın örneklemi ise 2018-2019 eğitim öğretim yılı güz dönemi Uşak Üniversitesi dördüncü sınıf öğrencileri arasından çeşitli aşamalar kaydedilerek belirlenmiştir. İlk aşamada genel tarama modeli kapsamında kotalı örnekleme usulü ile 400 kişilik örneklem çalışma evreni baz alınarak cinsiyet, fakültelerdeki öğrenci sayısı gibi faktörler göz önünde bulundurularak eşit bir biçimde yapılandırılmıştır (Karasar, 1984, s.115-156). İkinci aşamada ise belirlenen kotalar dahilinde basit tesadüfi şekilde seçilen 400 katılımcı araştırmanın örneklem kümesini oluşturmuştur. Çalışma 12-30 Aralık 2018 tarihleri arasında yüz yüze görüşülerek gerçekleştirilen anketler ile gerçekleştirilmiştir.

\section{Veri Toplama Araçlan}

Çalışma kapsamında "Sıkıntıya Dayanma (SDÖ)" ve "Sanal Ortam Yalnızlık (SOYÖ)" ölçekleri kullanılmıştır. Sanal Ortam Yalnızlık Ölçeği 
(SOYÖ) araştırmanın amacı doğrultusunda uyarlanmıştır. Veri toplama araçlarına yönelik detaylı bilgiler şu şekildedir;

Sıkıntıya Dayanma Ölçeği: Simon ve Gaher tarafından (2005). Geliştirilen "Sıkıntıya Dayanma Ölçeği (SDÖ)" bireyin sıkıntıya dayanmasındaki bireysel öz bildirimlerinin açılandığı toplamda 15 maddelik Likert derecesiyle seçeneklendirilmiş bir ölçektir. Türkçe'ye uyarlamasını ise; Sargın ve ark. (2012) gerçekleştirmiştir. İç güvenirlik (Alpha) kat sayıları ölçek genelinde .89 olup alt ölçeklerdeki değerler ise .90-.64 değerleri şeklinde değişim göstermektedir. İlgili ölçeğin alt boyutları, tölerans, regülasyon ve öz yeterlilik şeklinde tanımlanmıştır.

$\mathrm{Bu}$ araştırma kapsamında ise ilgili ölçek 3 faktör altında dağılım göstermiştir. Faktörlerin kapsadığı itemler göz önünde bulundurularak ilgili alt boyutlar, sıkıntıya dayanma, sıkıntıdan kurtulma ve olumsuz duygulanım şeklinde adlandırılmışlardır. Aynı zamanda ölçeğin geneli ile uyum göstermeyen 31, 33 ve 34'üncü maddeler çıkartılmıştır. Ölçek genelinde iç güvenirlik kat sayısı .78 olarak çıkarımlanmıştır.

Sanal Ortamda Yalnızlık Ölçeği: Korkmaz ve arkadaşları (2014) tarafından geliştirilen "Sanal Ortam Yalnızlık Ölçeği (SOYÖ)" ölçeği, kişilerin sosyalleşme temalı tutumlarını ortaya koyma amacı gütmektedir. İlgili ölçek toplamda 20 maddeden oluşmakta ve 5'li Likert tarzında seçeneklendirilen bir ölçektir. Sanal sosyalleşme, sanal paylaşım ve sanal yalnızlık olmak üzere 3 alt faktörden oluşan ölçeğin güvenirlik katsayısı (Alpha) .81 olarak belirlenmiştir. Alt faktörlerin güvenirlik kat sayıları ise .61 ile .84 arasında değişim göstermektedir.

$\mathrm{Bu}$ araştırma kapsamında ilgili ölçek paylaşma, sosyalleşme, yalnızlık ve güven temaları doğrultusunda 4 ayrı faktörde dağılım göstermiş olup, ölçeğin geneliyle uyuşmadığı gerekçesiyle 1. ve 10. maddeler ölçekten çıkarılmıştır. İç güvenirlik kat sayısı .77 olarak belirlenmiştir.

\section{Bulgular}

Katılımclar cinsiyete göre 200 erkek ve 200 kadın şeklinde dağılım göstermektedir. Yaşa göre ise 23 yaşındaki katılımcıların \%36.8, 22 yaşındakilerin \%31.5, 21 yaşındakilerin \%16 ve 24 üzeri yaştaki katılımcların \%15.8 oranla dağılım gösterdiği görülmüştür. 
Fakülte bazlı örneklem dă̆̆lım oranları ise şu şekildedir:

- \%21.5 İktisadi ve İdari Bilimler Fakültesi,

- \%20.3 Fen-Edebiyat Fakültesi öğrencileri,

- \%14.3 Mühendislik Fakültesi,

- $\quad \% 12$ Uygulama Bilimleri Fakültesi,

- \%11 Eğitim Fakültesi,

- $\quad \% 8$ İletişim Fakültesi,

- \%4.3 Sağlik Yüksek Okulu,

- $\quad \% 4.3$ Spor Bilimleri Fakültesi.

Katılımcıların (SOYÖ' den uyarlanan) SMYÖ ve SDÖ puanlarına ilişkin standart sapma ortalama değerleri ve $\mathrm{N}$ sayıları Tablo 1'de aktarılmıştır.

Tablo 1. SMYÖ ve SDÖ Puanlarna İlişkin Standart Sapma Ortalama Değerleri ve N

\begin{tabular}{llll}
\hline Değişkenler & $\mathbf{n}$ & $\mathbf{x}$ & Ss \\
\hline SMYÖ & & & \\
Paylaşım Boyutu & 400 & 2,6350 &, 80428 \\
Sosyalleşme Boyutu & 400 & 2,5194 &, 94297 \\
Yalnız Hissetmeme Boyutu & 400 & 3,7769 &, 80650 \\
Güven Boyutu & 400 & 2,5556 &, 57261 \\
\hline SDÖ(Toplam) & & & \\
Sikıntıya Dayanma Boyutu & 400 & 2,5763 &, 82748 \\
Sikıntıdan Kurtulma Boyutu & 400 & 3,3208 &, 95461 \\
Olumsuz Duygulanım Boyutu & 400 & 3,0617 & 1,00380 \\
\hline
\end{tabular}

Tablo 1'de görüldüğü üzere öğrencilerin "Sosyal Medyada Yalnızlık" bağlamında paylaşımda bulunma, sosyalleşme ve güven alt boyutlarına dair tutumları "orta" düzeyde iken yalnızlık tutumlarının ise "düşük" seviyede olduğu görülmektedir. Sıkıntıya Dayanma bağlamındaki tutumlarının ise "orta" derecede seyrettiği sonucuna ulaşılmıştır.

Katılımcıların SMYÖ ve SDÖ ölçeklerinden aldıkları puanlar arasındaki ilişkiyi incelemek maksadıyla Pearson Korelasyon katsayıları hesaplanarak ulaşılan sonuçlar ise Tablo 2' de gösterilmiştir.

Tablo 2'de aktarıldığı üzere katılımcıların paylaşım boyutu ile sıkıntıdan kurtulma $(\mathrm{r}=.125 ; \mathrm{p}<.05)$ ve olumsuz duygulanım $(\mathrm{r}=.114$; $\mathrm{p}<.05)$, alt boyutları arasında düşük seviyede pozitif anlamlı ilişki tespit edilmiştir. Öte yandan sosyalleşme alt boyutu ile sıkıntıya dayanma (r= 
.184; $\mathrm{p}<.01)$, sıkıntıdan kurtulma $(\mathrm{r}=.205 ; \mathrm{p}<.01)$ ve olumsuz duygulanım $(\mathrm{r}=.154 ; \mathrm{p}<.01)$ alt boyutları arasında da düşük seviyede pozitif yönde anlamlı ilişki olduğu görülmektedir.

Tablo 2. SMYÖ ve SDÖ Puanlarına İlişkin Standart Sapma Ortalama Değerleri ve N Sayıları

\begin{tabular}{lccc}
\hline Boyutlar & $\begin{array}{c}\text { Sikıntıya } \\
\text { Dayanma }\end{array}$ & $\begin{array}{c}\text { Sikıntıdan } \\
\text { Kurtulma }\end{array}$ & $\begin{array}{c}\text { Olumsuz } \\
\text { Duygulanım }\end{array}$ \\
\hline Paylaşım &, 93 &, $125^{*}$ &, $114^{*}$ \\
\hline Sosyalleşme &, $184^{* *}$ &, $205^{* *}$ &, $154^{* *}$ \\
\hline Yalnız Hissetmeme &,$- 187^{* *}$ &,- 030 &,$- 144^{* *}$ \\
\hline Güven &, 69 &,$- 100^{*}$ &, 051 \\
\hline${ }^{*} p<.05^{* *} p<.01$ & & &
\end{tabular}

Yalnız hissetmeme alt boyutuyla ise sıkıntıya dayanma $(\mathrm{r}=-.187 ; \mathrm{p}<.01)$ ve olumsuz duygulanım $(\mathrm{r}=-.202 ; \mathrm{p}<.01)$ alt boyutları arasında meydana gelen ilişkinin negatif yönde ve düşük seviyede bir anlam arz ettiği çıkarımlanmaktadır. Güven alt boyutunun ise yalnızca sıkıntıdan kurtulma alt boyutu ( $\mathrm{r}=-.100 ; \mathrm{p}<.05)$ ile düşük düzeyde negatif yönde anlamlı bir ilişki arz ettiği gözlemlenirken sıkıntıya dayanma ve olumsuz duygulanım alt boyutları ile arasında anlamlı bir ilişki olmadığı görülmektedir. Aralarında anlamlı bir ilişki tespit edilemeyen diğer alt boyutlar ise: "paylaşım boyutu ile sıkıntıya dayanma" ve "yalnız hissetmeme ile sıkıntıdan kurtulma" şeklindedir.

- $\quad$ Red: H1, H8, H10, H11

- Kabul: H2, H3, H4, H5, H6, H7, H9, H12

Bu doğrultuda araştırmanın amacı dâhilinde kurulan H2, H3, H4, H5, H6, H7, H9 ve H12 hipotezlerinin, düşük bir sevide de olsa anlam ilişki arz etmesinden dolayı kabul edildiği bulgusuna ulaşılırken H1, H8, H10 ve $\mathrm{H} 11$ hipotezleri ise reddedilmiştir.

Öte yandan sosyal medya kullanım sıklığı bağlamında katılımcıların: paylaşım, sosyalleşme, yalnız hissetme, güven, sıkıntıya dayanma, sıkıntıdan kurtulma ve olumsuz duygulanım boyutları kapsamında farklılık gösterip göstermediğini anlamak amaciyla One Way Anova testi gerçekleştirilmiştir. 
Tablo 3. One Way Anova Testi

Anova Sig. Test of Homogeneity of Variances Sig.

\begin{tabular}{lcc}
\hline Paylaşım &, 000 &, 114 \\
\hline Sosyalleşme &, 000 &, 168 \\
\hline Yalnızlık &, 050 &, 541 \\
\hline Güven &, 203 &, 572 \\
\hline Sikıntıya dayanma &, 003 &, 125 \\
\hline Sıkıntıdan kurtulma &, 000 &, 734 \\
\hline Olumsuz duygulanım &, 033 &, 333 \\
\hline
\end{tabular}

Tablo 3'te de aktarıldığ 1 üzere sosyal medya (SM) kullanım sıklığı bağlamında aralarında anlamlı farklılık olduğu görülen her alt boyut için Tukey Testi gerçekleştirilmiştir. İlgili test sonucunda 3 saat ve üzeri SM kullanan bireylerin;

- "Paylaşım" alt boyutu için 2 saat ve daha az SM kullanan bireylere göre ( $\mathrm{p}=.000-001 ; \mathrm{p}<.05)$ farklılaştı̆̆ 1 ,

- "Sosyalleşme" alt boyutu için 3 saatten daha az SM kullanan bireylere göre $(\mathrm{p}=.000 ; \mathrm{p}<.05)$ farklılaştığ 1 ,

- "Sıkıntıya Dayanma" alt boyutu için 1 ve 2 saat arası SM kullanan bireylere göre $(\mathrm{p}=.006 ; \mathrm{p}<.05)$ farklılaştığı,

- "Sıkıntıdan Kurtulma" alt boyutu için 1 saat ve 3 saat arası SM kullanan bireylere göre ( $p=.000-006 ; p<.05)$ farklılaştığ1,

- “Olumsuz Duygulanım" alt boyutu için 1 ve 2 saat arası SM kullanan bireylere göre $(\mathrm{p}=.027 ; \mathrm{p}<.05)$ farklılaştı̆̆ 1 tespit edilmiştir.

\section{Tartışma ve Sonuç}

Gerçekleştirilen bu araştırma kapsamında üniversite öğrencilerinin, sosyal medyadaki arkadaş ortamlarıyla gerçekleştirdiği paylaşımların, sıkıntıdan kurtulmayla ve olumsuz hislerden kaçışla kısmen de olsa ilişki arz ettiği görülmüştür. Bireylerin sıkıntılı ruh hallerinde sosyal medyada paylaşım gerçekleştirmelerine rağmen sıkıntıya dayanma noktasında sanal dünyanın tam manası ile bir ilişki içerisinde olmadığı yorumu yapılabilir. Öte yandan, kısmen de olsa sosyal medyanın problemlerden kurtulma ve içe kapanıklığı aşma noktasında tercih edilen bir iletişim 
aracı olduğu söylenebilir. Gerçekleştirilen bu çalışma sonucunda ulaşılan verilerin sonuçları ilgili ilişkilerin düşük seviyede gerçekleştiğini göstermektedir. Bu yönüyle çalışma çıktıları Yalçın'ın (2015: 64) bulguları ile örtüşmektedir fakat Yalçın’ın gerçekleştirdiği araştırmada ilişki seviyesi kısmen daha güçlü çıkmıştır. Öte yandan Özdemir, Akçakanat ve İzgüden'in (2017, s.134) araştırmasında ise üniversite öğrencilerinin sanal ortam yalnızlığına dair puanlarının genel itibariyle yüksek olduğu belirtilmiştir. Dolayısıyla çalışma bulguları Özdemir, Akçakanat ve İzgüden'in (2017, s.134) araştırma sonuçları ile örtüşmemektedir. Nitekim bu çalışmanın örneklemi bir çok fakültedeki öğrenci kümesi üzerinden oluşturulmuştur, öte yandan Özdemir ve diğerlerinin (2017) gerçekleştirdiği araştırmada ise örneklem olarak işletme bölümü öğrencilerinin tercih edildiği görülmektedir. Dolayısıyla katılımcıların sanal ortamdaki yalnızlıklarına dair ortalama puanlarının farklılık gösterme durumu bu eksende değerlendirilebilir.

Araştırma bulguları bağlamında bireyin gerçek yaşamda sahip olduğu değerlerin ve etkisi altında kaldığı faktörlerin, sıkıntıya dayanma noktasında daha elzem olduğu varsayılmaktadır. Çünkü çalışma kapsamında elde edilen verilere göre sosyal mecra ve sıkıntıya dayanma durumu arasındaki ilişki oldukça zayıftır. Genel bir kanaatle sosyal medyanın içinde yaşanılan gerçek dünyanın bir yansıması olarak ortaya çıktığı düşünüldüğünde ilgili varsayım daha da güçlenmektedir. Sosyal medya kullanımı 3 saat ve üzeri olan bireylerin daha az kullananlara göre genel olarak birçok boyutta farklılaşması da ilgili kanıyı destekleyen bir diğer çıktı olarak aktarılabilir.

Öte yandan alan yazında gerçekleştirilen sıkıntıya dayanma temalı çalışmaların çıktıları da bireylerin sıkıntıya dayanma durumları ile reel dünyadaki davranış ve yönelimlerinin (Köroğlu, 2018, s.29) daha ilişkili olduğunu gösterirken sanal mecra ile sıkıntıya dayanma durumu arasındaki ilişkinin düşük seviyede olduğunu (Yalçın, 2015, s.63; Erbaş, 2019,s.11-12) göstermektedir. Son olarak sıkıntıya dayanma noktasında sosyal medya temalı araştırmaların sebep sonuç ilişkisi çerçevesinde üçüncül değişkenler ile birlikte incelenmesinin alan yazına katkıda bulunacağı düşünülmektedir. 


\title{
EXTENDED ABSTRACT
}

\section{The Role of The Social Media On The Resistance Of The Individual To Distress}

\author{
Murat Sezgin - İdris Şimşek \\ Uşak University
}

The communication and socialization of human-who is temperamentally social-with other members of the society, is one of the unique factors that makes the individual adapt to society and life. Those who can not fulfill this function internally feel lonesome and at the same time could feel excluded from the community.

Social media that gains ground with Web 2.0 in our lives has caused the patterns of communication and interaction among individuals to evolve and transfer of communication and interaction to the virtual environments; based on this point of view, a lof of studies have been conducting in the field; starting from related studies, within the scope of this research,the relation between social media and endurance to distress has been handled.

\section{Purpose, Importance and Limitations of Research}

The fact that most of the university students continue their education in a city other than the environment in which they are born and raised also removes them from their existing social environment.In this respect, individuals continue their lives with their newly acquired social environment and benefit from social media environments with the purpose of getting rid of their loneliness and distress.In this context, it is thought that the relationship between social media usage and the difficulties of students is seen as a subject worth studying.Therefore, the aim of this study is to investigate the relationship between the use of social media and loneliness 
caused by loneliness in relation to various sub-dimensions. The general hypotheses of the research are as follows;

H1 There is a significant relationship between the size of sharing and the size of the students.

H2 There is a significant relationship between the size of sharing of students and the size of getting rid of them.

H3 There is a significant relationship between the size of sharing and negative affect dimension of students.

H4 There is a significant relationship between the socialization dimension of the students and the size of difficulty.

H5 There is a significant relationship between the socialization dimension of the students and the size of getting rid of them.

H6 There is a significant relationship between the socialization dimension of students and the negative affect dimension.

H7 There is a meaningful relationship between the size of the students' feeling of being alone and the size of the difficulty.

H8 There is a significant relationship between the size of the lonely feeling of the students and the dimension of getting rid of them.

H9 There is a significant relationship between the loneliness dimension and the negative affect dimension.

H10 There is a significant relationship between the trust dimension of the students and the size of difficulty.

H11 There is a significant relationship between the trust dimension of the students and the size of the disability.

H12 There is a significant relationship between the trust dimension of students and the negative affect dimension.

In this context, although it is emphasized in the literature that social media is an important stakeholder of our lives by changing daily habits (Köseoğlu, 2012, p.76-77; Alican and Saban, 2013, p.13), the role of social media in embarrassing individuals is dealt with as empirically. Field researches are quite limited (Yalçın, 2015, p.63; Özdemir, Akçakanat, İzgüden, 2017, p.133-134). Therefore, this study is important in terms of literature in terms of addressing the role of social media in getting rid of boredom. On the other hand, the studies in the related literature are quite 
limited (Özdemir, Akçakanat, İzgüden, 2017, s.133-134; Yalçın, 2015, p.63; Erbaş, 2019, p.11-12), and the sample sets are concentrated on certain themes. It is thought that the study outputs will contribute to the literature. As a matter of fact, the selected sample in this study was not chosen through a specific faculty or department, and it was preferred over a study universe that could represent a wide range of university students. Therefore, research results can be generalized to the study universes which are considered as university students. On the other hand, the limitations of the research; factors such as budget, time and transportation. Considering the relevant constraints, the study universe was preferred considering the ease of transportation.

\section{Methodology}

\section{Universe and Sampling}

The environment of study has composed of forth grade(Senior) students of the University of Uşak; as for the sampling of study, it has been conducted step by step out of the forth grade students of Uşak University in the fall semester of the 2018-2019 school year; in the first stage, within the scope of general survey model, a sampling distribution of 400 persons has been constituted by the method of quota sampling (Karasar, 1984: 115156). In the second stage,quotas which have been determined according to the sampling distribution, have been applied to the randomly chosen participants. This study has been carried out with the questionnaires conducted face to face.

The distribution of the participants is 200 females and 200 males; the proportion of participants by ages is as below:

$\begin{array}{cc}\text { Age } & \text { Percentage } \\ 23 & 36.8 \% \\ 22 & 31.5 \% \\ 21 & 16.0 \% \\ 24 & 15.8 \%\end{array}$


In the context of "Loneliness in Social Environment", while the attitudes of the students related to the sub-dimensions such as sharing, socialization and relaibility are moderate, it is seen that the attitudes related to loneliness are marginal.The attitudes of students in the context of "Endurance Distress" are moderate.

In order to examine the relation between (SMYÖ) and (SDÖ) points of the participants,Pearson Correlation coefficients were calculated and in the end, it has been seen that there is a low-level positive connection between sharing size and sub-sizes as Relieving from Distress $(r=.125 ; \mathrm{p}<.05)$ and Negative Emotion(r=.114; $<$.05) of the participants.On the other hand, it has also been observed that there is a low-level positive connection between socialization size and sub-sizes as Endurance Distress $(\mathrm{r}=.184 ; \mathrm{p}<.01)$, Relieving from Distress $(\mathrm{r}=.205 ; \mathrm{p}<.01)$ and negative emotion $(\mathrm{r}=.154 ; \mathrm{p}<.01)$.

It has been deduced that there is a low-level negative connection Between not Feeling Loneliness sub-size and the sub-sizes as Endurance Distress $(\mathrm{r}=-.187 ; \mathrm{p}<.01)$ and Negative Emotion( $\mathrm{r}=-.202 ; \mathrm{p}<.01)$.As for the Reliability sub-size,it has been observed that there is a low-level negative connection between Reliability sub-size and Relieving from Distress sub-size $(\mathrm{r}=-.100 ; \mathrm{p}<.05)$ only; whereas any meaningful connection between Reliability sub-size and the sub-sizes as Endurance Distress and Negative Emotion has not been observed.The other sub-sizes which do not demonstrate any meaningful connection in between are those; "Sharing and Endurance Distress" and "Not feeling Loneliness and Relieving from Distress".

Denied: H1, H8, H10, H11

Approved: H2, H3, H4, H5, H6, H7, H9, H12

Accordingly, within the scope of survey (study), the hypotheses $\mathrm{H} 2$, H3, H4, H5, H6, H7, H9, H12 have been accepted because they represent meaningful connection even if it is at a low level, whereas the hypotheses H1, H8, H10, H11 have been rejected.

Within the scope of this developed survey, it has been observed that the sharings of the university students with their friends in the social media present a connection,even if it's partly, with relieving from distress and 
escaping from negative feelings. Although the individuals in their distressful moods carry out sharings in social media, it can be commented that the social world isn't in interaction entirely. On the other hand, it can be said that the social media is a preferable means of communication in connection with overcoming the problems and relieving the introversion. The data obtained as a result of this study has shown that the related relations have actualized at a low level.

\section{Kaynakça / References}

Alican, C. ve Saban, A. (2013). Ortaokul ve lisede öğrenim gören öğrencilerin sosyal medya kullanımına ilişkin tutumları: Ürgüp örneği. Erciyes Üniversitesi Sosyal Bilimler Enstitüsü Dergisi, 1(35), 1-14.

Blanco, V. A. (2014). Dijital Çağda Boş Zamanın Dönüşümü. Sosyal Medya Devrimi, E. A. Pilgin (Çev.), B. Çoban (yay. haz). içinde (185-199). İstanbul: Su Yayınevi .

Buckner, J. D., Keough, M. E. ve Schmidt, N. B. (2007). Problematic alcohol and cannabis use among young adults: The roles of depression and discomfort and distress tolerance. Addictive behaviors, 32(9), 1957-1963.

Carey, J. W. (1967). Harold Adams Innis and Marshall McLuhan. The Antioch Review, 27(1), 5-39.

Cüceloğlu, D. (2006). Insan ve davranışı (15. Bsm): İstanbul: Remzi Kitapevi. Duğan, Ö. (2018). Sosyal medya kaynaklı krizlerin imaj restorasyon teorisi açısından örnek olaylar üzerinden incelenmesi. Akdeniz İletişim Dergisi, 29, 293-313.

Ellis, R. (1994). The study of second language acquisition. Oxford and Oxford English are trade Marks of Oxford University Press, Printed in China.

Erbaş, S. (2019). Facebook yalnızlık rehabilite merkezi mi? Journal of The Cukurova University Institute of Social Sciences, 28(1), 1-16.

Erdoğan, İ. ve Alemdar, K. (2005). Öteki kuram: Kitle iletişim kuram ve araştırmalarının tarihsel ve eleştirel bir değerlendirmesi. Ankara: ERK Yayınları.

Evans, D. (2008). Social media marketing: An hour a day. Canada: Willey Publishing. 
Franch, A. L. ve Carrillo, M. (2014). Çevrim içi finansal habercilikte sosyal medyanın benimsenmesi: Sosyal medya devrimi, E. A. Pilgin (Çev.), B. Çoban (yay. haz) içinde (233-246) İstanbul: Su Yayınevi.

Göker, G. (2015). İletişimin Mcdonaldlaşması: Sosyal medya üzerine bir inceleme. Electronic Turkish Studies, 10(2), 389-410.

Güler, Ş. (2018). Halkla ilişkiler öğrencilerinin mesleki kaygılarının ölçülmesine yönelik bir ölçek geliştirme çalışması. Gümüşhane Üniversitesi İletişim Fakültesi Elektronik Dergisi, 6 (2), 1046-1072. Doi: 10.19145/e-gifder.441006.

Güngör, N. (2011). İletişim: Kuramlar ve yaklaşımlar, 1. Baskı, Ankara: Siyasal Kitabevi.

Jarvis, J. (2012). E-sosyal toplum: Dijital çağda sosyal medyanın iş gündelik hayata etkisi, Ç. Kök (çev). 1. Bsm, İstanbul: MediaCat Yayınları.

Kara, T. (2013). Sosyal medya endüstrisi, 1. Baskı. İstanbul: Beta yayınları.

Karasar, N. (2004). Bilimsel araştırma yöntemi. Ankara: Nobel Yayınevi.

Kaya, A. (2013). Sosyal paylaşım ağlarının kişilerarası iletişim sürecine etkisi bağlamında Facebook: Sosyalleşen birey, Sosyal Medya Araştırmaları, A. Büyükaslan, M.A. Kırık (ed.) içinde (155-206). Konya: Çizgi Kitapevi.

Kırık M. A. (2013). Gelişen web teknolojileri ve sosyal medya bağımlılı̆̆ı: Sosyalleşen birey. Sosyal Medya Araştırmaları 1, A. Büyükaslan, M.A. Kırık (ed.) içinde (69-102). Konya: Çizgi Kitapevi 69-102.

Konrad, S. ve Hendl, C. (2001). Duygularla güçlenmek: Duygusal zekâ sayesinde başarılı bir hayat, M. Taştan (Çev.). İstanbul: Hayat Yayınları.

Korkmaz, Ö., Usta, E. ve Kurt, İ. (2014). Sanal ortam yalnızlık ölçeği (soyö) geçerlik ve güvenirlik çalışması. Hacettepe Üniversitesi Eğitim Fakültesi Dergisi, 29(29-2), 144-159.

Köroğlu, K. (2018). Üniversite öğrencilerinde sıkıntıya dayanma ve alkol kullanımı arasındaki ilişkide başa çıkmanın rolü. Yüksek Lisans Tezi, Işık Üniversitesi, İstanbul.

Köseoğlu, Ö. (2012). Sosyal ağ sitesi kullanıcılarının motivasyonları: Facebook üzerine bir araştırma. Selçuk Üniversitesi İletişim Fakültesi Akademik Dergisi, 7(2), 58-81. 
Leyro, T. M., Zvolensky, M. J. ve Bernstein, A. (2010). Distress tolerance and psychopathological symptoms and disorders: A review of the empirical literature among adults. Psychological bulletin, 136(4), 576.

Morgan, C. T. (2011). Psikolojiye giriş. S. Karakaş R. Eski(Ed.), Hacettepe Üniversitesi Psikoloji Bölümü Yayınları (Çev.) 19. Bsm. Konya: Eğitim Kitap Evi Yayınları.

Murphy, J., Hill, C. A. ve Dean, E. (2013). Social media, sociality, and survey research. RTI International Wiley: North Carolina.

Özdemir, S., Akçakanat, T. ve İzgüden, D. (2016). Internet çağında sanal ortam yalnızlığı: Üniversite öğrencileri üzerine bir araştırma. Süleyman Demirel Üniversitesi Vizyoner Dergisi, 8(19), 125-136.

Sanlav, Ü. (2014). Sosyal medya savaşları, 1.Bsm, İstanbul: Hayat Yayın Grubu.

Sargın, A. E., Özde, K., Utku, Ç., Kuru, E., Alkar, Ö. Y. ve Türkçapar, M. H. (2012). Sıkıntıya dayanma ölçeği: Geçerlik ve güvenilirlik çalışması. Bilişsel Davranış̧̧ Psikoterapi ve Araştırmalar Dergisi, 1 152-161.

Sayımer, İ., (2012). Sanal ortamda halkla ilişkiler, 2. Bsm, İstanbul: Beta Yayınları.

Shih, M., Hootman, J. M., Strine, T. W., Chapman, D. P. ve Brady, T. J. (2006). Serious psychological distress in US adults with arthritis. Journal of general internal medicine, 21(11), 1160-1166.

Simons, J. S., ve Gaher, R. M. (2005). The distress tolerance scale: Development and validation of a self-report measure. Motivation and Emotion, 29(2), 83-102.

Steinberg, A. (2014). Genç seçmen ve web 2.0 ile politik katılım: Facebook genç vatandaşların seçime katılımını arttırabilir mi?. Sosyal Medya Devrimi, E. A. Pilgin (Çev.), B. Çoban (yay. haz). içinde (154-171), İstanbul: Su Yayınevi

Svendsen, L. F. H. (2008). Sıkıntı'nın felsefesi, M. Erşen (Çev.), İstanbul: Bağlam Yayıncılık.

Tarhan, N. (2012). Duyguların psikolojisi (12. Bsm). İstanbul: Timaş Yayınları. 
TDK, (2019a). http://www.tdk.gov.tr/index.php?option=com gts\&arama=gts\&kelime $=\mathrm{s} \% \mathrm{C} 4 \% \mathrm{~B} 1 \mathrm{k} \% \mathrm{C} 4 \% \mathrm{~B} 1 \mathrm{nt} \% \mathrm{C} 4 \% \mathrm{~B} 1$ Erişim Tatihi, 09.01.2019

TDK, (2019b). http://www.tdk.gov.tr/index.php?option=com gts\&arama $=$ gts\&kelime $=\% \mathrm{C} 3 \% \mathrm{BCz} \% \mathrm{C} 3 \% \mathrm{BCnt} \% \mathrm{C} 3 \% \mathrm{BC}$ Erişim Tarihi: 09.01.2019

Vaag, J., Bjørngaard, J. H. ve Bjerkeset, O. (2016). Symptoms of anxiety and depression among Norwegian musicians compared to the general workforce. Psychology of music, 44(2), 234-248.

Yalçın, G. (2015). Sosyal medyanın yoğun kullanımının ileri ergenlikte yalnızlı ve depresyona etkisi. Yüksek Lisans Tezi, İstanbul Arel Üniversitesi, İstanbul.

\section{Kaynakça Bilgisi / Citation Information}

Sezgin, M. ve Şimşek, İ. (2019). bireyin sıkıntıya dayanması üzerine sosyal medyanın rolü. OPUS-Uluslararası Toplum Araştırmaları Dergisi, 11(18), 1259-1281. DOI: 10.26466/opus.537720 